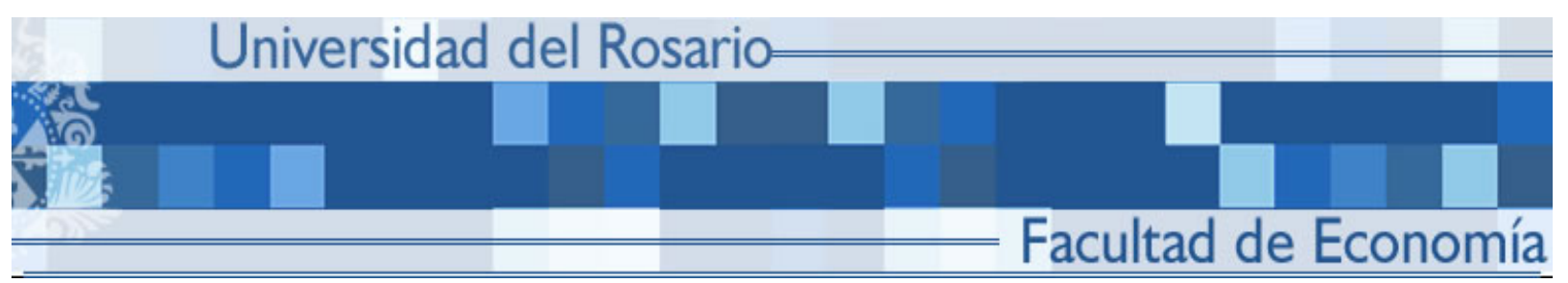

\title{
AGRICULTURAL SECTOR AND COMPETITION POLICY IN COLOMBIA
}

Ricardo Argüello C

María Clara Lozano 0 de Z

\section{SERIE DOCUMENTOS DE TRABAJ O}

No. 28

Noviembre de 2007 


\title{
Agricultural Sector and Competition Policy in Colombia
}

Ricardo Arguello C. and María Clara Lozano O de Z.

\begin{abstract}
In this chapter we provide a summary description of Colombian Competition Policy with an emphasis on the agricultural sector. Key developments and recent changes in institutional arrangements affecting competition policy, as it applies to the agricultural sector, are highlighted. Illustrative case studies are depicted to show the richness and complexity of policy developments and enforcement. Some general conclusions are drawn from this examination.
\end{abstract}

JEL: K21, D49, Q13

Keywords: Competition Policy, Agriculture, Colombia

August, 2007

- Draft chapter. Forthcoming in Latin American Antitrust Developments (Nova Science 2008 expected), D. Daniel Sokol, editor.

* Ricardo Arguello C., Department of Economics, Universidad del Rosario

María Clara Lozano Ortiz de Zarate, Law Faculty, Universidad Javeriana and Lozano \& Asociados 


\section{Introduction}

In this chapter we review competition policy and law in Colombia with an emphasis on the agricultural sector. For this analysis, we first visit the legal and institutional structure of competition policy and its implementation from a historical viewpoint. Then we examine the legal and institutional relationship between competition law and agricultural policy as well as the role for competition policy in agricultural development. This chapter examines a number of cases investigated by the authorities to illustrate the main issues involved in implementing competition policy in the agricultural sector.

After several decades in a dormant state, competition policy in Colombia had a major shake up with the opening up of the economy and the revamping of competition law and institutions. During the last fifteen years there has been a substantial increase in the use of competition policy. Several high profile cases have tested both the adequacy of competition law and the legitimacy and capability of the relevant authorities. With the passage of time and the increase in the number of cases investigated, the competition agency has gained experience and enhanced its expertise for promoting a competitive environment in Colombian markets.

The use of competition policy in regulated or quasi regulated sectors is of particular interest. Even though currently there is no extensive governmental intervention in the agricultural sector, the state intervenes in important ways in the functioning of agricultural markets. Several policy instruments have been put in place that effect competition. Moreover, more open markets and the increasing involvement of the Colombian agricultural sector in a market environment have made competition issues arise in important ways. Competition issues affect not only relatively complex organizational and property structures, typical of a modern economic sector, but also truly atomistic and dispersed producers more akin to a peasant economy.

Disciplining the market, in the sense of guaranteeing its competitiveness, has different implications for different agents. As we will see, it can mean curbing the appetite of oligopsonists for determining purchasing prices, and therefore protecting the primary producers, or it may mean teaching primary producers that they cannot collude to hurt consumers. This ample range of market outcomes provides the environment in which competition and agricultural policies interact.

The relevance of examining the agricultural sector is further highlighted if we take into consideration that it accounts for about $14 \%$ of GDP and $23 \%$ of total employment in Colombia. These shares may well triple if we include sector linkages upstream and downstream. Furthermore, there is an important aspect to Colombian agricultural development: its dualistic nature. As in other developing countries, the agricultural sector has historically been characterized as having two distinct segments. On one side, a modern, technologically developed segment and fully linked to the market. On the other, 
a relatively backward, technologically stagnated segment only partially linked to the market.

This characterization has become fuzzy with the development of the Colombian agricultural sector and with improved technology diffusion and adoption. As a result, the technologically and market based dualism has tended to shift to a size based dualism, in which issues such as effective access to credit, to new technologies, and to marketing circuits are the dominant features determining market outcomes. For several products, scale economies and minimum efficient scale in handling and processing determine market entry. A number of sectors, among it cocoa processing, sugar production, rubber processing, tobacco processing, snacks production, rice milling, and dairy processing, show moderate to high concentration levels in Colombia.

In these circumstances, having competitive markets is essential to agricultural development. Competitive markets provide the most efficient way to bridge the gap between large and small producers. Competition policy has an obvious and key role to play in generating and keeping markets competitive. It also has an important role in safeguarding domestic agents against international anti-competitive practices, whether they originate abroad or at home. In the face of increasing concentration in key international markets and in view of evidence of anti-competitive behavior, greater openness and market deregulation do not substitute for competition policy.

\section{Competition Law in Colombia}

Colombia has the oldest competition law among Andean Countries. Issued in 1959, Law 155 provided the first attempt to promote competition in Colombia. The law addresses three antitrust areas: interlocking of positions in boards of directors and administrative officeholdings, traditional business anti-competitive practices, and mergers and acquisitions. Regarding restrictive business practices (RBP's), law 155/59 contains a general statement prohibiting all conduct intended to restrain competition. However, it does not provide specific examples of anti-competitive conduct. This may be a reason why there were practically no cases brought before the authorities until the 1990s when legislation was supplemented. This disposition also provides some criteria in order to identify companies with market power.

At the same time, law 155 of 1959 gives the government the power to allow agreements that, although may be considered as anti-competitive, are deemed necessary for stabilizing an economic sector that is regarded as "basic" to the economy. ${ }^{1}$ The definition of "basic" sector is found in another piece of legislation, dated 1964, and is so broad that practically any economic sector may qualify as such. ${ }^{2}$

\footnotetext{
${ }^{1}$ There is an interesting discussion regarding who is the authority in this case. In its Circular Unica (General Statute) issued in 2001, the SIT indicates that the agency is the only one that can grant the exception. However, there is a legal definition of government in the Colombian constitution: the government is the president and the corresponding Minister. Therefore as the government is the grantor of the exception, it would be the president and the corresponding minister who are allowed to do so.

${ }^{2}$ Decree 1302 from 1964
} 
Regarding mergers, the law establishes a mandatory pre-merger notification procedure. By this, firms whose combined assets are worth more than twenty million Colombian pesos (about US\$10,000, an adequate figure for that time) must submit to the authorities any plan for merging in order to obtain prior approval. As will be explained below, this threshold has been changed twice in recent years. The measure is intended to evaluate the likelihood that the proposed merger may inadequately restrict competition. The law does not give any specific content to this concept, and the antitrust agency has applied different criteria for judging different cases in this area

The liberalization of the Colombian economy from the late 1980s to early 1990s, necessitated an updated Colombian competition law and policy. The Colombian Political Constitution amended in 1991, provided in Article 20 the authorization to give a new structure to the Colombian state. Following this constitutional disposition, the Colombian executive issued Decree 2153 of 1992, which contains substantial dispositions regarding antitrust matters and the corresponding new structure of the Colombian antitrust agency.

Decree 2153 supplemented Law 155 and reinforced the powers of the competition agency while significantly reducing the degree of governmental discretion in competition issues. The decree created specific prohibitions and provided for a more objective assessment of violations through the establishment of a set of specific standards. It also provided a clear definition of the basic antitrust concepts related to conduct and structure, a list of specific exceptions to the application of Colombian competition law, such as R\&D agreements. Another exception is made for efficiency justifications in mergers cases. However, to date, the Superintendency of Industry and Trade (SIT) has yet to approve a merger based on an efficiency exception..

The definition of the term "agreement" provided by Decree 2153 does not make any difference between horizontal and vertical agreements. Therefore, the specific prohibitions of articles 47 and 50 of the decree determine if they apply to horizontal or vertical conducts. An open question in enforcement is whether to use per se or rule of reason standards. This question is before the Council of State (Colombia's top administrative authority) and a decision on the matter is still pending. On unilateral conduct, the Colombian Political Constitution (as amended in 1991) provides that it is illegal to abuse a dominant position in a market.

Decree 2153 set the current institutional structure of Colombian competition policy. It created a new structure for the already existing SIT, which the Decree charged with the enforcement of competition law, other than that related to specifically regulated industries. The SIT is an independent body of the executive branch, headed by a Superintendent. In addition to its competition policy function, the SIT oversees consumer protection and management of the intellectual property rights system, and supervision of the chambers of commerce. 
Regarding competition policy, a deputy superintendent for the promotion of competition is charged with investigations and merger analysis. His/her office conducts investigations and analyses proposed mergers, prepares investigation reports, including conclusions of law, and submits them to the Superintendent for final adjudication. During the adjudication process, the Superintendent has the obligation to consider recommendations from an Advisory Committee, created by Decree 2153, but does not have to abide by them. The Superintendent adjudicates the cases on the basis of his/her own discretion and may even depart from the conclusions put forward by the deputy Superintendent on whether to impose sanctions and fines. The SIT's decisions may be reviewed only by the administrative courts.

In addition to its enforcement function, the SIT has a competition advocacy role. Among other activities, it can advise other government agencies on matters related to regulations affecting market entry and competition issues in natural monopolies and privatizations. Remedies used by SIT for enforcing competition, include: an order to rectify or cease any conduct contrary to law, fines of up to 2,000 minimum legal monthly wages (approx US\$ 440,000 ) on companies involved and of up to 300 minimum legal monthly wages (approx USD 65,000) on persons. Importantly, the Colombian Political Constitution of 1991 declare the right to competition as a collective right. This allows, besides private rights of action, antitrust class actions.

Sector regulators are the primary enforcers of competition in regulated sectors. - The Superintendency of Domestic Public Services ensures competition in the supply of domestic public services. However, the SIT investigates restrictive trade practices in nonresidential telecom services. Also, the Financial Superintendency is charged with investigating antitrust issues in the banking and insurance sectors. Regarding TV services, the National Television Commission (CNT) is the authority. Nevertheless, there has been a recent and interesting agency case where the SIT has claimed authority to review a merger case (Telmex - Cablecentro - Supercable; all providers of TV cable services) due to the fact that the companies revoked their licenses in order to perform the operation. According to SIT, at the moment the firms renounced their licenses the CNT lost while the SIT gained the jurisdiction to review the merger.

\section{Competition Policy Implementation}

During the first three decades of competition law in Colombia, the SIT never prosecuted a case. ${ }^{3}$ This appears to be partly the consequence of infant-industry and importsubstitution protectionism, which allowed the consolidation of monopolies and oligopolies in almost every industrial sector. The intricate relationship that followed between powerful firms and conglomerates on the one hand and government officials and politicians on the other was not the best environment for an effective competition policy. Furthermore, the general prohibition statement of Law 155 refers to the need of "unfair" prices developing as a consequence (potential or actual) of the anti-competitive conduct, a hard concept to define and use practically within an investigation procedure. Lastly, as

\footnotetext{
${ }^{3}$ Jatar and Tineo, 1997
} 
mentioned, the law did not provide examples of anti-competitive conduct. This left application of competition law in a regulatory vacuum.

Since 1992, when the SIT began operations under the new legal framework, a number of important cases have been investigated. As in the case of other Andean countries, the emphasis has been on behavior rather than structure, a feature that is credited with making the enforcement of competition policy less traumatic for the economy than trying to correct market structure (in terms of number of competitors or degree of concentration). The emphasis on behavioral remedies (not to the exclusion of structural remedies) is particularly important, given the uncertainty of determining the optimal size of firms in the market.

The Superintendent has the power to close a competition investigation if the defendant pledges sufficient guarantee (similar in concept to a consent decree) that it will cease or amend the conduct under investigation. As collateral for compliance with offered remedies, companies must take an insurance policy on the SIT's benefit. Whenever the SIT considers that there has been non compliance with the commitments acquired, it can start a process in order to proof the lack of compliance and made effective the insurance policy. The insurance company is allowed to go after the company undertaking the policy due to its non compliance. The ability to crate guarantees has led to a significant number of case settlements. Though guarantees have led to swift settlement of cases, it prevents the SIT from issuing final decisions. The lack of final decisions limits the development of needed jurisprudence and enforcement precedents. Furthermore, having the discretion to settle this way even cases involving violations that are analyzed as per se restrictions in other jurisdictions seems contrary to the development of a competition culture. Not to mention the fact that consumers can not recover the social cost implied by certain restrictive practices and that the negotiating process for determining the guarantees is not ruled. Compliance with guarantees has been an issue in recent years. When the SIT has found non-compliance it has imposed fines and has made effective the corresponding insurance policies. One recent example of non-compliance is the SIT's imposition of substantial fines in August 2007 to several cell phone companies. The fines were based on the lack of compliance regarding non-discrimination agreements regarding the origin of phone calls (cellular or fixed telephony).

Merger control is a large part of the SIT's antitrust enforcement. The Circular Unica (General Statute) from the SIT, issued in 2001, establishes the notification requirements for potential merging parties. Merging parties must receive prior approval from the agency when the merging parties have at least 20 percent of market share or jointly have assets for a value equivalent to 50,000 monthly legal minimum wages. Afterwards, Resolution 22195 of 2006 lifted the threshold for prior approval to 100,000 monthly legal minimum wages (more than US\$22 million) of combined annual operational revenue or combined total assets without mentioning any threshold regarding market share. The long awaited measures were intended to rationalize the review process, which due to the now inadequate threshold established in Law 155 tended to clog up SIT's operational capability. According to the SIT, the market share threshold was eliminated from the regulation due to its lack of objectivity and legal uncertainty. 
Of non-merger enforcement, the vast majority of cases relate to agreements regarding price fixing, output restraints, and market allocation. Cases related to resale price maintenance conduct and the refusal to deal have also been prominent and very complex.

\section{Agricultural Sector and Competition Policy Law}

Colombia's competition legislation is fully applicable to the agricultural sector. However, article 65 of the Colombian Political Constitution provides for special protection regarding food production. Moreover, Decree 2478 of 1999, establishing the structure and functioning of the Ministry of Agriculture, includes an article that addresses competition issues. ${ }^{4}$ The latter allows the Ministry to regulate domestic agricultural markets, determine price policy for these goods and their inputs when there are market failures, and to submit to the relevant agencies requests for issuing policy measures aimed at correcting the internal competition environment. The Agricultural Ministry has used this power in only one case, as discussed further herein.

Even though there are a number of areas within agricultural policy in need of greater competition, the SIT has undertaken little competition advocacy in the agricultural sector. This in spite of the fact that a number of sector policy instruments have clear effects on competition and that the legislation that creates them lacks any mention to competition law. There is frequent potential tension between sector policy and competition policy. This is driven by the fact that sector policy is often aimed at protecting rural income (or the income of certain rural groups) through direct or indirect price setting and other mechanisms, among them transfers from some economic agents to others or market regulation. The "disconnect" that used to exist between the Ministry of Agriculture's policies and the SIT created a vacuum that has proved negative for enhancing competition in the agricultural sector, as well as for successfully implementing sector policy in the long run.

An example of the disconnect between the Agricultural Ministry and the SIT, is a Concept ${ }^{5}$ from the Chief of SIT's Legal Advisory Office (Concept 25623 of 2000) in response to a consultation as to whether Resolution 321 of 1999 from the Ministry of Agriculture, by which a Price System and Framework for the Operation of Dairy Markets in Colombia (implementing parts of a Competitiveness Agreement for the Dairy Sector, brokered by the Ministry of Agriculture between private agents from the sector and the government in 1999), could be in violation of competition law. The SIT recalls the general prohibition for subscribing accords with anti-competitive effects, as well as the exception to this discipline when there is need to stabilize a basic sector of the economy. The Concept asserts that the Competitiveness Agreement was issued in July 1999, before the issuing of Resolution 321, and that there is no document in the files of the SIT proving that the agency had conceded or had been requested to issue any authorization in

\footnotetext{
${ }^{4}$ The reference is to numeral 15 of article 3 , that states what the main text mentions.

${ }^{5}$ Under Colombian law, a concept is a non binding interpretation of law issued by an authority.
} 
this regard. ${ }^{6}$ Therefore, if it were any norm in the Competitiveness Agreement that could be in violation of competition law, the Ministry of Agriculture's Resolution would be protecting a conduct that is contrary to Constitutional principles and law. Nonetheless, the Concept highlights the fact that the Ministry's Resolution is an administrative act protected by presumption of legality and that unless being suspended or declared null by the administrative courts, this presumption would have to be taken into consideration for assessing its legality. This example underscores the difficulties inherent (from the legal and economic points of view) in providing for a regulatory framework for agricultural activities and competition promotion.

The "disconnect" we have already mentioned between the two agencies seems to be less severe. The Ministry of Agriculture has begun to explicitly intervene in competition matters in the sector. Moreover, there has been increased coordination between the Ministry and the SIT. The apparent reason is the push by organizations and their members in the food system regarding potential and actual anti-competitive practices in this sector. There is an international element to this concern regarding international cartels.. As a function of improved inter-governmental concern in this area, the Colombian government, particularly the Ministry of Agriculture, has started to intervene for correcting alleged anti-competitive practices in several subsectors. An additional factor pushing greater competition has been proposed free trade agreement with the United States. These factors, led private agricultural organizations to propose that the Ministry of Agriculture propose competition norms for the sector. Though this effort ultimately failed, it exemplifies a shift in orientation on competition in agriculture in Colombia. Partly as a consequence of this effort, in 2005 the SIT and the Ministry of Agriculture started an ambitious program related to the establishment of an agriculture competition group inside the SIT: the Interinstitutional Agricultural Follow Up Group. The intent is to have a specialized technical group to study mergers and acquisitions, and restrictive business practices investigations in this sector. The Ministry of Agriculture funds the agricultural competition group of the SIT. It consists of seven staff, most of them with two bachelor degrees. ${ }^{7}$

In July 2005, the Ministry of Agriculture under its authority from Decree 2478 issued Decree 2513 to define the term "unfair" price (required for the application of the general prohibition contained in article 1 of Law 155) as it applies to the dairy sector. Decree 2513 also established that the Ministry would consult the SIT in cases in which the Ministry suspects anti-competitive practices or unfair price setting in the raw milk market. However, this definition was temporary in its nature and remained in place just for around a year.

In September 2005, the Ministry of Agriculture issued Decree 3280 . Decree 3280 refers to how the SIT should handle requests for agreements aimed at agricultural stabilization of food production and distribution. In particular, the Decree provides that the power to

\footnotetext{
${ }^{6}$ A non surprising fact given the ambiguity as to who the authority is for granting the exception for stabilizing a basic sector. However, competitiveness agreements, similar in scope and depth to the above mentioned exist for agricultural sectors that clearly are not in need of special stabilization measures.

${ }^{7}$ SIT's competition promotion branch has 14 people besides the agricultural group.
} 
authorize such agreements belongs to the SIT but that the Superintendent should ask for an ex-ante non-binding recommendation (called a "concept")from the ministries of agriculture and trade. The concept must refer to the need for sector stabilization. It also provides for previous and non-binding concept from these Ministries when the Superintendent analyzes the possibility of finishing the agreement for considering that the sector has already been stabilized.

A further development of inter-institutional cooperation relates to the issuing by the Ministry of Agriculture of Resolutions 00128 and 00125 of June 2006. The first provides policy guidance for determining prices for agrochemical products while the second subjects the market of these products to vigilance by the Ministry (a controlled freedom regime $^{8}$ ). According to the Ministry of Agriculture, the measures address old complaints from agricultural producers in the sense that agrochemical plants and distributors make use of anti-competitive practices, price fixing in particular. The controlled freedom regime is extended to other agrochemical and agricultural inputs in November 2006 (Resolution 00302) and in April 2007 (Resolution 0092) firms in the agrochemical sector $^{9}$ were required by the Ministry to submit information on prices, production costs, sales, goods, and distribution (a power the Ministry has under the controlled freedom regime).

The implementation of price interventions in order to attain competition enhancements has not been a pacific issue in Colombia . This case was no exception. In view that a number of firms have not complied or have done so in an incomplete fashion, the Ministry asked the SIT to directly request information on compliance, making use of a feature of the controlled freedom regime and the power of SIT to impose sanctions to those that do not comply with STI requests Based on this request, in June 2007, the SIT required 300 firms that were not complying, to submit the information within a twenty calendar day window (until July 10th). No compliance ${ }^{10}$ entails a fine of up to 2,000 monthly legal minimum wages (about US\$437,000). The measure has a precedent in a previous Resolution by SIT, issued in March 2007, by which the agency fined five agrochemical firms for not fulfilling their obligation to report market and price information to the Ministry of Agriculture. To the end of July, it was clear that a number of cases of lack of reporting were due to firm closings without fulfilling all legal procedures, and therefore they were not operating. Other cases were due to mistakes in reporting on the part of the firms. Lastly, a number of cases, about 100, were effectively cases of lack of or misrepresenting reporting.

The Ministry increasingly has made use of policy instruments to increase competition in the sector. One such example is the so called "absorption accords" created from 1995. These accords were agreements brokered by the Ministry of Agriculture, the Ministry of Trade, and the Ministry of Finance, between private agents by which the right to import

\footnotetext{
${ }^{8}$ A situation in which firms are allowed to freely set their prices, but are obliged to inform the authorities, in written, about their variation and the way they are determined, in accordance to a methodology determined by the authorities.

${ }^{9}$ This included producers, mixers and importers.

${ }^{10}$ A similar situation occurred in the banking sector where 5 banks that refused to send information were recently fined by the SIT.
} 
under preferential arrangements was conditioned on purchases of domestic product, and a purchasing price was agreed upon. ${ }^{11}$ However, in this, as in other cases, legislation creating the policy had no explicit mention of either competition policy or to a role for the SIT.

\section{The Role for Competition Policy in Agriculture}

Even in a developing country such as Colombia, the agricultural sector tends to be significantly market oriented. Having a dynamic agricultural sector, in the sense of increased productivity, is vital not only for improving social conditions in rural areas but also for economic development in general. Competition policy affects the way agents in agricultural production behave as much as how they relate to other sectors in the economy, and may prove to be an important tool in helping develop a dynamic agricultural sector.

For producers, having the capacity to substitute inputs with relatively elastic supply for inputs with inelastic supplies is a key factor in improving efficiency and returns. However, market structure may tend to hinder this possibility. By far, markets for agricultural products, such as corn, fuits and vegetables, and many ohers, are much less concentrated than markets directly related to the sector, such as agrochemical products, agroindustry, and massive retail sales. Although market concentration does not necessarily lead to anti-competitive behavior, it favors the development of market power and creates conditions favorable for asymmetric bargaining power. Of course, there is a trade off between fairness and efficiency, especially evident when there are economies of scale in a market. But, nonetheless, asymmetries between the more competitive agricultural production and other markets that integrate the whole food and raw materials chain could be of concern.

There are several potential forms of market power in the agricultural sector. The scale of operation of firms with which agricultural producers relate (upstream and downstream) and the degree of concentration in these markets may tend to favor sustained price fixing at levels lower than the competitive one. Vertical integration or coordination may also lead to producers losing their economic surpluses, as some research in the context of developed countries has tended to show. Non-competitive contracting is usually the means for this. Asymmetric information, barriers to entry, conditional access to technological innovation, and even agency capture, are also ways in which market power may be exerted. Even though none of these forms have been documented to happen in Colombia, there is always the potential for them to develop as the market becomes more and more complex and competition intensifies, making firm survival more challenging.

From the above, it is clear that there is a potentially important role for competition policy in helping foster agricultural development. However, the right mix between agricultural and competition policies can not be determined a priori. There is need to consider the

\footnotetext{
${ }^{11}$ This instrument is no longer used, since it was replaced by a system for auctioning import rights based on purchases of domestic product.
} 
particular conditions that prevail in a market on a case by case basis so that the trade-off between the two policies may be assessed. This is so in as much as there are noneconomic objectives being pursued by agricultural policy. There is also a clear need for a better understanding of the international context and its relation and influence on national markets.

The Ministry of Agriculture has demonstrated its concern regarding some of these related markets. Such is the case of agrochemical products production and distribution, a sector that shows a relatively high degree of concentration. The Ministry's concern relates to the potential influence of agrochemical agents' behavior on the agricultural chain of production, especially on the way it may affect farmers' capability for taking advantage from more productive inputs.

The marketing and distribution sector is also undergoing an accelerated concentration process, at least at the higher end of the chain. The SIT investigated large retailers such as Carrefour, Exito (Casino's French Group), Carulla and Olimpica ${ }^{12}$ for: (1) violation of the general prohibition of article 1 of law $155 / 59 ;^{13}$ (2) anti-competitive discrimination; (3), exploiting suppliers; (4) threatening suppliers with decodification of their products; and (5) abuse of collective dominant position against suppliers. ${ }^{14}$ The investigation ended with guarantees. ${ }^{15}$ One guarantee was an Agreement on Good Practices and Consumer Protection (AGPCP) ${ }^{16}$ signed by the main associations of suppliers and distributors of Colombia. ${ }^{17}$

Recent mergers and acquisitions in the supermarket segment have led to dominance of the market by three big players. In conducting merger review for a proposed merger between two of the biggest supermarket chains in the country (Exito and Carulla) the SIT

\footnotetext{
${ }^{12}$ This investigation was opened by Resolution 24180 of 2002.

${ }^{13}$ A number of types of conduct fall within this prohibition, among them selling below the cost of acquisition.

${ }^{14}$ Conducts investigated under the violation of article 50 of decree 2153 were: predatory pricing; discrimination; tying; uncompliance with agreed terms for payment; forced request of free products for new sale points; unexplained devolution of products; pressure procedures to grant the same conditions of other hypermarkets; forced request of product's revenue warranty in case of other competitor's promotions; mandatory and almost permanent promotions charged without authorization to the suppliers; threats to decodify products as a negotiating tool with suppliers; unilateral determination of the logistic operator charging its price to the supplier.

${ }^{15}$ Resolution 13466 of 2004

${ }^{16}$ The AGPCP is a binding 35 page long document that provides regulation on the following aspects: (i) predatory pricing; (ii) commercial agreements and payment terms; (iii) unilateral charges by the hypermarket; (iv) negotiation and execution of commercial agreements; (v) promotion campaigns; (vi) exhibition of products in the hypermarket; (vii) devolutions; (viii) deceptive information; (ix) codification of products and suppliers (requirements); (x) proper trademarks; (xi) decodification; (xii) breach of conditions in promotions; (xiii) Information for suppliers; (xiv) prohibition of the obligation that similar conditions had been previously given to other hypermarket; (xv) opening of new sale points; (xvi) conditions for the suppliers; (xvii) sales people of the supplier in the hypermarket; (xviii) retaliation. Additionally, the AGPCP provides a procedure for having private resolution of conflicts between hypermarkets and suppliers before having recourse to the SIT.

${ }^{17}$ One of the authors negotiated the AGPCP.
} 
imposed conditions to approval. To neutralize the competitive concerns of the merged firms negotiating power vis-à-vis its suppliers, the STI conditioned approval on ExitoCarulla to: (i) comply with the AGPCP; (ii) act according to the following restrictions regarding fresh and important consumption products: (a) eliminate exclusivity; (b) eliminate preferential clauses; (c) eliminate exclusivity clauses in technology and maquila contracts; (d) no ability to request competitors' prices or discounts; (e) nondiscrimination of suppliers; (f) no retaliation against the denial of a supplier to provide information on prices and terms given to other competitors; (g) no retaliation against suppliers' granting different terms (e.g., pricing) to competitors, or to tie terms to the ones given to Exito-Carulla; and (h) not to condition the acceptance of price increases to previous negotiation of this price with competitors. The SIT also imposed a structural condition. The merged company must divest 11 stores (Resolution 34904, December 2006). ${ }^{18}$

Some markets in the processing sector have become increasingly concentrated. One such market is dairy sector. As mentioned earlier, government intervention has been warranted for providing a definition of "unfair" prices-the first time the term has been defined under Colombia's competition law. The government also established a price setting mechanism for raw milk, at a high cost in terms of implementation, monitoring, and resistance from affected parties.

Increased trade openness and the need to secure supplies and solve coordination issues, have been the reasons behind the surge of different forms of vertical coordination and integration. Integration may be of concern as agents may act as sellers or buyers of agricultural produce, giving them more leverage on the market. In the same direction, as vertical integration develops, markets for raw materials and intermediate inputs tend to lose depth and price signals weaken.

\section{Illustrative Cases}

This section provides a number of representative cases to provide an overview of the key issues in competition policy and law pertaining to the agricultural sector.

\section{Price fixing and market allocation agreements in the agrochemical industry}

As mentioned, the agrochemical industry has been under scrutiny from the Ministry of Agriculture for several years now. In a related case, by Resolution 15847 of 2006 the SIT opened an investigation against two of the largest firms in the fertilizer industry (Monomeros Colombo Venezolanos and Abonos Colombianos). The conducts under investigation were price fixing and market allocation in six types of fertilizer, all of them put by the Ministry of Agriculture under the controlled freedom regime. While under investigation, both firms offered the SIT guarantees to cease their conduct and provide the SIT information on compliance.

\footnotetext{
${ }^{18}$ The SIT approved the sale of the 11 stores to Olimpica in 2007.
} 
Under Resolution 3119 of 2007, the SIT accepted the guarantees. The guarantees included commitments by the firms to: independently determine their prices; establish a Production and Marketing Committee for marketing policies and to deter and adopt criteria for pricing; and to inform to the SIT of any anticipated price changes and the motivation for such changes. The SIT accepted similar guarantees regarding market allocation (in terms of production and imports). The SIT also required the firms to subscribe insurance policies with a value equivalent to a $100 \%$ of the maximum fine that it could charge the firms and their legal representatives (approximately US\$440,000 and US\$65,000, respectively). ${ }^{19}$

Price fixing, market allocation, conditioned sales, and obstruction of market entry agreements in the sugar sector

By Resolution 12305 of 2001, the SIT opened a cartel investigation against a set of 11 sugar producers (the bulk of the Colombian sugar industry) and a marketing company (Dicsa). The marketing company was created by the sugar producers with the aim of commercializing and promoting the consumption of sugar and molasses in the national market. The firm had a contract with sugar producers by which it sells in the market molasses that are provided by sugar producers. The preliminary investigation considered that the sugar producers set up Dicsa such that: Disca had exclusivity in trading; the sale price was the same for each sugar producer; Disca, by contract, had to assign in an equitable fashion to the sugar producers the sale of molasses and to inform the producers of the conditions of sales; and that in the sales contracts the molasses buyers had to commit to use molasses an input for feedstock only (no human consumption). Disca had the power to inspect and impose economic penalties in the case of breach.

The firms under investigation offered the SIT guarantees to terminate it. The offer included an end to price fixing for sugar or molasses and a commitment to inform the SIT with respect to any variation in the prices of these products. Additionally, sugar producers committed to avoid granting Dicsa exclusivity in the trade of raw sugar and molasses. They also committed to modify the sales contracts in order to eliminate the conditions objected to by the SIT.

The SIT accepted the guarantees and required the firms to subscribe insurance policies for a value equivalent to $40 \%$ of the maximum fine that it could impose on them and on their legal representatives (the firms had offered to take insurance policies for an equivalent of $10 \%$ the maximum fine). It also required the firms to determine, at the level of the board of directors, explicit procedures for the determination of sugar and molasses prices and to ensure that these procedures would be followed at any time.

\footnotetext{
${ }^{19}$ Under Colombian law, when an "economic agent” (typically a firm) offers guarantees it does not accept any liability in the case. The SIT's final decision in an enforcement matter that has a guarantee only covers the sufficiency of the guarantee to amend or eliminate the conduct in question that raises competition concerns in the specific case.
} 
Price fixing (for ethanol production purposes and sugar production) and market allocation agreements in the sugar sector

In March 2007, by Resolution 6381, the SIT opened investigation against 13 sugar processors for price fixing. The investigation followed complaints by sugar cane producers. The alleged practices took place between May 2005 and February 2007. Preliminary evidence points towards the existence and use of a unique formula to determine the price of sugar cane on the part of the sugar processors for ethanol production. The facts also signal that sugar cane producers do not have the freedom to choose the sugar processor to which to sell. The case remains open.

Price fixing agreements in the pasteurized milk market

In January 1997, the president of the Association of Independent Milk Processors gave a press declaration stating that starting that day (January $25^{\text {th }}$ ) the price of the one litter milk bag would be COLP\$600 in the Bogota market. In view that by February of the same year, a set of 11 milk processor and distributors has indeed fixed a sale price of COLP\$600, the SIT decided to open an investigation for price fixing against these processors and plant owners. The SIT closed the case in 2000 under Resolution 27762. The SIT established that there was price fixing behavior on the part of at least two processing plants. It ordered them to cease the price fixing and fined the firms.

Abuse of Dominant Position: Discriminatory conditions, conditioned sales, and obstruction of market entry in the milk sector

In 2002, the National Association of Entrepreneurs (ANDI) complained before the SIT against a milk cooperative (Colanta) for abuse of dominant position in the milk market against milk producers from whom Colanta bought raw milk. According to the ANDI, Colanta conditioned the entry of new members to the cooperative to the purchase of Colanta's feedstock. In response, the SIT opened an investigation. It found no connection between buying feedstock from the cooperative or being a member on terms for raw milk sales. On the contrary, the conditions applying to milk sales were deemed objective and responsive to the market environment. It also found that there was no conditionality related to the purchase of feedstock from the cooperative or of acceptance as a cooperative member. Under Resolution 588 of 2003, the SIT ruled that even though the cooperative has a dominant position in the relevant market, it has not exerted market power or abused of its dominant position.

\section{Abuse of dominant position in the coffee export market}

In 2001, through Resolution 30616, the SIT opened an investigation against the National Federation of Coffee Growers (Fedecafe) and two private coffee exporters associations for abuse of dominant position. Fedecafe has acted for a long time as a marketing board for coffee, controlling an important share of the market as a buyer in the domestic market and exporter. The case was brought by SIT on several counts. First, the SIT considered that the allocation of export quotas and of agreements for exclusive supply to certain 
international buyers (that have to register before Fedecafe), may have limited access to other exporters and hindered free trade. According to SIT's analysis, Fedecafe and the two associations agreed to assign export quotas in a 3:7 proportion in detriment of new entrants or of non-affiliated exporters, especially small ones. Furthermore, the three associations appear to have participated in an agreement for setting buying prices for coffee in periods in which the grain was in short supply. The SIT was suspicious that the participants in the agreement would abuse its joint dominant position in by excluding competitors.

The associations offered guarantees to the SIT to: terminate the conduct in question; to not enter into agreements with each other or with individual exporters that may imply export quota allocations or quotas for buying exportable coffee; to not fix prices; and to provide non-discriminatory conditions in buying or exporting coffee for non-affiliated firms. As usual, the associations committed to supply the SIT information necessary to monitor compliance with the guarantees, and the SIT accepted insurance policies as collateral for the offer (the amount was fixed at $50 \%$ of the maximum fine that the SIT could have imposed on the associations and their legal representatives). The guarantees were accepted by the SIT under Resolutions 3361 and 19923 of 2003.

\section{Price fixing agreements in the rice sector}

In 2000 two rice producers associations complained to the SIT of price fixing by five rice milling companies in their purchasing. The SIT opened an investigation on the matter (Resolution 2249 of 2000). The rice millers offered guarantees to cease the price fixing. The SIT accepted the guarantees and closed the investigation (Resolution 15645 of 2001). Subsequently, the rice producers filed an additional complaint of price fixing. The SIT concluded that purchase price by the millers was similar across a 591 days period and that occasional price variations were graduated in such a way that average prices were identical between millers. In view of this, the SIT issued Resolution 7347 of 2003, which nullified Resolution 15645 of 2001 and opened a new investigation. The guarantees tried to be made effective by the SIT giving rise to a series of legal procedures that have not ended yet.

In September 2005, as a result of a new investigation issued because of a complain by rice producers, the SIT issued Resolution 22625 against the same two milling companies for price fixing for paddy rice purchases in the central part of the country, and imposed heavy fines to the firms and their legal representatives (based on the past history of price fixing). The firms offered guarantees and stop this behavior, which the SIT accepted under Resolution 15645. In December 2005, the firms asked the SIT to void Resolution 22625 based on the SIT's violation of due process and the right to defense ${ }^{20}$ and for the

\footnotetext{
${ }^{20}$ In this particular case, the investigated party considered that its right of defense was violated by the SIT because: (a) the latter rejected the request to consider void a recourse previously presented by the investigated party (given that it was signed by the attorney formerly representing the party); (b) the SIT did not consider evidence provided by the party in another request; (c) the SIT considered as non pertinent a request to declared void its previous decision; and (d) because the SIT upheld the totality of its previous findings and decisions.
} 
SIT lack of consideration of relevant evidence. The SIT contested the firms' arguments of the firms and upheld Resolution 22625 in its entirety.

M\&A: Breach of the obligation to report a merger in the poultry sector

Under Resolution 11030 of 2002, the SIT opened an investigation against a set of four poultry producers and an agricultural firm created by them for not filing for pre-clearance of the merger under Colombia's merger review process. The SIT concluded that the firms competed in the relevant product market of the purchase of feedstock for maize and soybeans in both domestic and export geographic markets. The SIT viewed that this was a case of vertical integration and that given the value of combined assets of the poultry producers, this necessitated merger review. The SIT closed the case under Resolution 8315 of 2003 and imposed fines. We consider that this case was a collaboration agreement among competitors and not a merger between the poultry firms, less a vertical integration and that the SIT's reasoning is problematic.

\section{M\&A: Breach of the obligation to report a merger in the banana sector}

In July 2002 (Resolution 25186), the SIT opened an investigation against a banana trading company, a holding company, and a set of eight banana producers for failing to report a merger for review. The investigation established that the trading company had

acquired from a third party (another holding company) all of the assets of the holding company under investigation. The latter had the control over the eight banana producers. With the acquisition the trading company indirectly took control over the banana producers. The SIT considered that the trading company, the holding company that was acquired by it, and the banana producers should have previously informed the operation. By Resolution 21820 of 2004, the SIT determined that the firms had the duty to get prior approval for the merger. Though the firms disputed the need for pre-merger clearance, the SIT prevailed on the merits and Resolution 28515 of 2004 upheld Resolution 25186 in almost its entirety.

Abuse of dominant position: predatory pricing in the mushroom sector

The SIT opened an investigation in 2002 (Resolution 20893) against a mushroom producer for predatory pricing. The case contains a lengthy discussion about the relevant market, both in terms of the product and of the geographical market. The SIT determined that the firm's size, market share, and production level as well as the sunk costs that other incumbents or new entrants in the market would have to incur in to increase supply demonstrated a dominant position by the producer. However, in reviewing the case, the Office of the Superintendent partially departed from the conclusions of competition promotion branch of SIT arrived. After examining the behavior of the firm's prices (among other relevant factors during the period analyzed), and taking into account marketing costs (which the competition promotion branch ignored), the SIT concluded that there had been no predatory pricing under Resolution 30835 of 2004. 
Wholesale and supply restrain in the scallions market -

The 2003 OAS Report on Development and Enforcement of Competition Policy and Laws in the Western Hemisphere, reports a case of market allocation and supply restrain in the scallions market in Bogotá. The report asserts that a complaint by a trader against three traders and Bogota's wholesale market (Corabastos) was issued before the SIT for the alleged dividing-up of markets among distributors and for agreements that affect the level of production of the good. The SIT carried out an investigation to determine whether Corabastos and the traders had signed an agreement, known as the "Acta de Transaccion”, by which they aimed at output and territorial restrictions.

In its investigation, the SIT found the agreement and evidence of its implementation. The fourth clause of the agreement indicated that Corabastos would not authorize the wholesale distribution and selling of scallions on the premises of the warehouse market. As a consequence, sellers who leased stores in Corabastos were forced to sell their scallions to the leaseholders participating in the agreement. The SIT fined Corabastos and the other investigated parties.

Another price fixing case in the scallion market occurred in 2007, when local media reported on a practice by scallion producers for restricting supply during the largest harvest season. Scallion production supplying Bogota's market comes almost entirely from a town in a neighboring department (Aquitania, Boyaca). The vast majority of producers are small farmers, cultivating no more than 2 or 3 hectares. Due to the rain pattern, the biggest harvest occurs during November. Bogota's market has a well known absorption level for this product and prices drop sharply when it is surpassed. To avoid price declines, producers colluded to restrict the number of trucks leaving Aquitania to Bogota to limit output. In view of the news, the SIT decided to open an investigation against several of the leaders of the community for restricting supply. The investigation is currently under way.

\section{Conclusions}

The quest for a dynamic agricultural sector has an important contributing factor in counting on competitive markets at the first stages of the value chain, so that technological innovation and adoption is enhanced. An elastic supply of high productivity inputs is needed to secure that benefits stay in the agricultural sector and higher returns drive further technological change. Gains in productivity may be threatened by market power and asymmetries in the interplay between primary producers on the one hand and processors, distributors, and retailers on the other.

Therefore, having competitive markets at the primary producers level as well as in markets where they interact with other segments of the value chain (input producers, processors, traders, and retailers) is critical for agricultural and economic growth. Hence, competition policy can play an important role in helping secure favorable conditions for 
agricultural development. However, there are inherent tensions between agricultural and competition policy. These derive from the fact agricultural policy often seeks to tilt the balance in favor of specific rural groups and tends to do so by intervening in the market in ways that may be anti-competitive. Striking the right balance between agricultural and competition policies is then at the cornerstone of governmental intervention in the sector.

After decades of neglect, it seems that agricultural and competition policies in Colombia have begun to explicitly and intentionally interact. This appears to have been largely determined by the participation of the private sector. Increased openness to international markets, a greater degree of concentration in key industries, and better information on competition policy seem to be among the driving forces for private sector activism.

We can draw a number of lessons on Colombian competition policy in the agricultural sector. Even though the cases are meant to be illustrative, they show the richness that agricultural and agricultural related markets have in terms of competition policy enforcement. The cases range from the analytically simple cases of lack of prior reporting and approval of a merger to elaborate and complex of conducts (and firms' intertwined property) in the sugar or banana sectors. Cases also range from firms in oligopsonic markets attempting to abuse their dominant position to small producers trying to protect their income by avoiding price decreases.

Cases have been brought via the request of affected parties or by via SIT itself. The former originate in private agents' knowledge of competition policy and the rights and protections it entails them. The latter originate in SIT's organizational mission to promote efficiency and the competitive process. While both help to bring greater competition to agricultural markets, they clearly differ in spirit as the former may be regarded as the product of a competition culture that seems to be slowly but firmly growing, whereas the latter are part of the process of creating such a culture. The former also potentially may be abused as competitors attempt to have the SIT open investigations as a business strategy to increase the costs for firms under investigation.

There is no doubt that agriculture has been an active field in competition policy in the last decade in Colombia. Though late to enforcement in the agricultural sector, competition policy has become significant and effective. A mixture of market developments and governmental intervention against anti-competitive practices both inter-institutionally across government agencies and on the part of the SIT are the basis for this development.

A multidimensional learning process has been taking place in Colombian competition policy. The SIT has gained expertise and has started to develop a still limited but unprecedented knowledge of domestic agricultural markets. It has (implicitly) come to the recognition that to maintain a competitive agricultural sector demands a level of expertise that the SIT has yet to develop. Private agents in the sector have learned and continue to do so about competition policy about their rights and obligations. Governmental agencies, in particular the Ministry of Agriculture, have seemingly learned the importance of interagency coordination and support for competition policy enhancement. There is also learning at more complex levels. With experience, the SIT 
has gained greater political legitimacy and capability in handling sensitive cases, such as the coffee case. Still, a fully developed competition culture is a long way away.

Even though positive in general terms, the lessons from competition policy implementation for the agricultural sector are not all rosy. From the standpoint of implementation, at least two issues merit attention. First, it is important to examine the role of guarantees in antitrust procedures. Even though it seems to be an adequate tool for attaining the goals of a SIT investigation, recourse to negotiating and offering guarantees has tended to be taken for granted, as past experience illustrates. Moreover, compliance with guarantees' commitments has not always been strong. To date, the SIT has opened several investigations regarding non-compliance of guarantees, and had made effective the insurance policies. To create better compliance of guarantees, the SIT has imposed fines on non-compliant firms. As cases of repetitive non-compliance tend to show, there is the possibility that the procedure may open the door to undermining law enforcement and weakening the development of a competition culture. Adding to the complexity of guarantees is that the procedure for offering and negotiating guarantees is not subjected to explicit rules, which exposes the process to uncertainty. This calls for greater transparency.

Second, even though there has been important progress in interagency coordination, a systematic examination of the competitive effects of sector policy instruments needs to be undertaken. The main issues involved, no doubt, will be put on the table sooner or later, as new cases will be brought for investigation, as some of the cases currently underway directly or indirectly touch upon this area. However, from the point of view of the private sector for greater predictability, clearly it is undesirable that sector policy collide with competition policy. This possibility is detrimental for both sector and competition policies and may have a negative impact in creating a competitive environment.

In sum, recent developments in competition policy and its implementation, as they apply to the agricultural sector, show an important dynamics in Colombia. As a result, a positive environment for developing a competition culture in the sector has arisen and a multidimensional learning process is taking place. Interagency coordination has increased and a body of jurisprudence is beginning to develop. However, the country still has a long way to go to get a fully fledged competition culture for this sector (and the economy at large). A review of the role that guarantees play in policy implementation and enforcement, and a systematic review of the potential competitive effects of some sector policy instruments, are among the more important tasks that seem to be needed for enhancing the process currently underway. 


\section{References}

Organization of American States, 2002, Inventory of Domestic Laws and Regulations Relating to Competition Policy in the Western Hemisphere

Organization of American States, 2003, Report on Development and Enforcement of Competition Policy and Laws in the Western Hemisphere, FTAA Negotiating Group on Competition Policy, FTAA.ngcp/inf/04/rev.2/January 15

Owen, Bruce, 2003, “Competition Policy in Latin America”, John M. Olin Program in Law and Economics, Stanford Law School, Working Paper 268, October

De Leon, Ignacio, 2000, “A Market Process Analysis of Latin American Competition Policy”, Paper presented at the UNCTAD Regional Meeting on Competition Law and Policy, San Jose, Costa Rica, 30 August-1 September

Jatar, Ana Julia and Luis Tineo, 1997, Competition Policy in the Andean Countries: A Policy in Search of its Place, Inter-American Dialog and OAS, http://www.sice.oas.org/compol/articles/cpandea.asp, accessed June 2007

Ibarra, Gabriel, 2004, "Politica de Competencia y Sector Agricola en Colombia -Agenda de Negociaciones Comerciales”, in Andres Espinoza (ed.) La Agricultura Colombiana Frente al Tratado de Libre Comercio con Estados Unidos, Ministerio de Agricultura y Desarrollo Rural - Bolsa Nacional Agropecuaria

Superintendency of Industry and Trade, several Resolutions and Concepts 